\title{
Study on the Safety of Computer System As Well As Its Application
}

\author{
Zhao Hong-li, Zeng Xiao-hui \\ NanChang Institute of Science \& Technology
}

\begin{abstract}
With the development of information technology, computer system has become increasingly important for the whole country as a support for social activities. Any destroy or failure of computer system will contribute to huge influence on the whole society. It is of great and direct importance to study the safety of computer information system. In the paper, much importance has been given to the safety principles for the application of computer system, development of information system, safety levels, safety service and safety structure models. Besides, according to the study, safety of computer network is a comprehensive and complicated system project, which needs to be maintained regularly by improving people's awareness of computer network safety. By studying and accumulating knowledge, people's skills in computer safety can be constantly improved.
\end{abstract}

Keywords-computer; network safety; safety of information system; system optimization

\section{INTRODUCTION}

The constant development of computer science and technology with the wide application of computer has promoted the social progress and prosperity, which has brought humans with huge fortune. In particular, the development of computer network has made information sharing applied to various fields like finance, trade, business, enterprise and education and so on. The computer network is characterized with wide distribution, open system structure, resource sharing and channels sharing and so on, so network is seen as practical; Meanwhile, due to the features of online storing, sharing and transmission, information can be eavesdropped, intercepted, altered and even destroyed illegally, which may cause immeasurable losses with a weak system correspondingly. Thus, it is of great realistic significance to explore the safety of computer system.

The safety of computer system refers to safety theories and strategies, computer safety technologies, safety management, safety evaluation, safety products as well as computer crimes and detection, computer safety laws and safety auditing.

DOD (TCSEC) was issued formally by the United States Department of Defense in 1985, which divides computer safety levels into four varieties and seven levels. The seven levels are D, C1, C2, C3, B1, B2, B3 and A1 successively.

The paper introduces current development situations of computer information system safety home and abroad, studies network safety technologies, safety technologies of database, code technologies and firewall technologies; besides, it studies and analyzes the safety strategies and measures adopted in the application and development of computer information system combined with safety technologies of computer information. Then it takes the development and construction of management information system of a certain scientific project as an example to specifically explain the system design, database design as well as main functions of system models. Meanwhile, it further explores how to construct and develop a complex and safe information system according to safety levels and structural model of computer information system by employing safety technologies of computer information so as to make improvement on applied system and database system.

\section{SAFETY LEVELS OF COMPUTER SYSTEM}

\section{DEVELOPMENT}

Apart from solving many problems of traditional C/S, $\mathrm{B} / \mathrm{S}$ also has many other advantages for its convenient operation, stable property, safe and reliable remote data transmission, low cost, easy maintenance as well as independent client software. At present, it has been a mainstream system of network applied system. The environment of system development is mainly distributed network structural environment with the 
adoption of TCP/IP network protocol, which can realize the functions of distributed processing, resource sharing, data sharing, multiple-clients supporting, synchronous operation and access of multiple programs. Safety levels of the whole system are shown as Fig .1 below.

\begin{tabular}{|c|}
\hline External part of the system \\
\hline clients \\
\hline application programs \\
\hline DBMS \\
\hline OS \\
\hline $\begin{array}{c}\text { hardware(machine, network as well as other } \\
\text { equipment) }\end{array}$ \\
\hline
\end{tabular}

Figure 1. Safety levels of the system

1. The first level is hardware, which aims to realize network safety by network safety technologies.

2. The second level is operation system, which sets controls on the access of different customers.

3. The third level is database level. DBA is responsible for daily management, maintenance, recovery and backup pf database; Besides, it sets sensor. During its usage, clients and data can be separated without complete access and update of the list so as to raise safety.

4. The fourth level is application programs, which restricts the protection on data safety to recording level and field level, but such kind of restriction should give consideration to two aspects. First, the strong controlling strength will bring low efficiency and less inflexible programs. Second, the work of DBA will become quite complicated for relatively larger application system. Therefore, besides some important data, the controlling granularity is not expected to be too strong so as to achieve a macro data control of application programs.

5. The information safety can be realized by controlling clients' access with the adoption of access monitor Fig .2 is a model of access monitor.

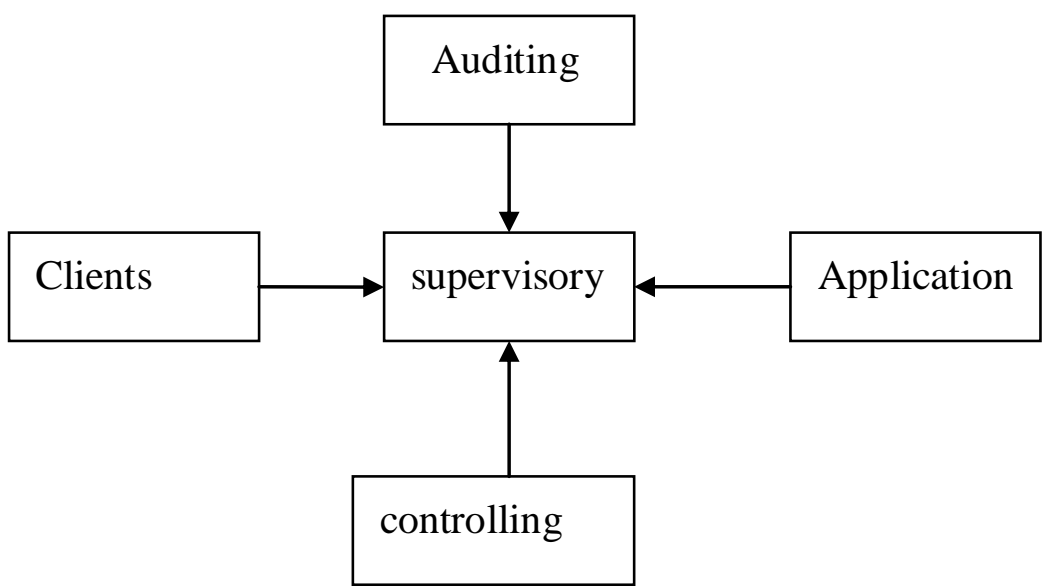

Figure 2. Model of access monitor 


\section{STRUCTURAL MODEL OF COMPUTER SYSTEM}

Computer system is a complicated technological system. From its structural description, it should include infrastructure, systematic structure and basic functions. See Fig .3.

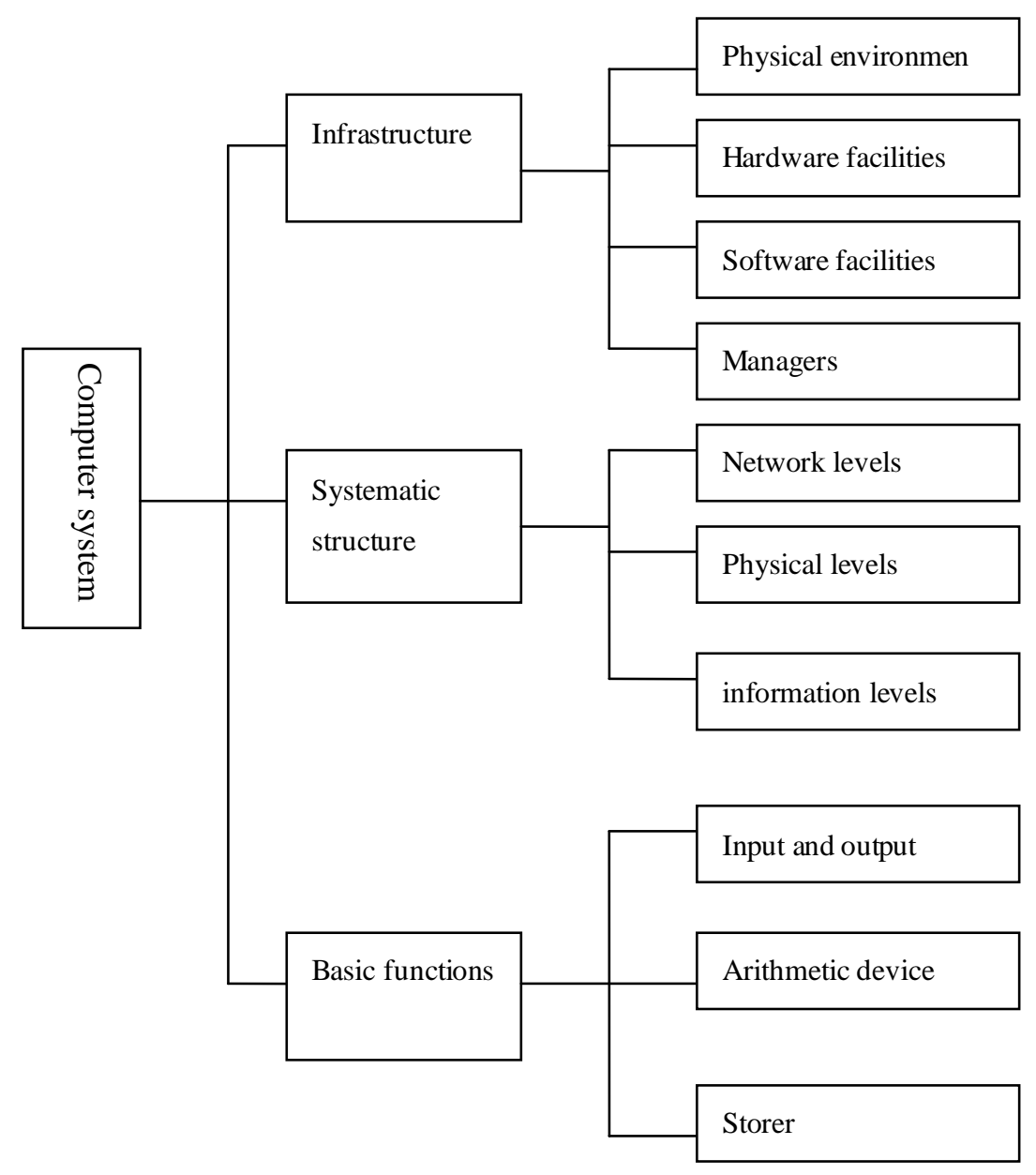

Figure 3. Structure of computer system

\section{A. Prevention of computer virus}

The invasion of computer virus is difficult to be noticed with various means, so we need to pay more attention by installing anti-virus software with comprehensive properties; and meanwhile computer system should be upgraded frequently so as to avoid damage from virus. Virus protection is an important part of daily maintenance and safety management for computer system, so both users and system managers should pay attention to it. There are related prescriptions for virus prevention during the usage and management system of computer system. Related staff should master the usage of anti-virus software and anti-virus card and so on to avoid virus invasion with regular inspect on computer virus. If computer is invaded by virus, effective measures should be taken immediately to recover the operation and affected data timely. Thus, preparations should be made in advance by copying important data and information to prevent data from losing or damaging. The common software are 360 virus defender, Kaspersky, Rising, KV3000, NOD32 and Kingsoft Antivirus and so on. 


\section{B. Anti-Hacker technology}

At present, more and more hackers are damaging our daily network application and even human rights, so identity certification is becoming more and more important. Users need to alter their codes regularly combined with other management technologies to prevent computers from the attacks of hackers. The most direct means is to employ firewall technology. It means to set firewall between external network and local area network after the computer is linked to network so as to separate local area network from external network. Thus, IP address of local area network can't be located by external network directly.

\section{Completely eradicate junk emails}

Junk mails have gradually become another damage of computer network safety. In order to eradicate junk mails, we need to first protect our own email address without random registration by using email address. Meanwhile, junk emails can be filtered with the mail management of outlook express and foxmail so as to reject junk mails.

\section{CONCLUSION}

With the deep development of information network technology as well as rapid development of Internet, network crimes caused by computers have risen constantly with diversified network attacks. Besides, network threats also become diversified, such as economic fraud by faked legal website, interception and capture, change and imitation of electronic information. Actually, the main reason is from controlling. In the computer system, its application control is basically program control. As the computer system is operated with continuity, repetition and high speed, huge risk will be caused if there is certain bugs. Therefore, measures of computer controlling should be designed effectively so that system can be safer during operation.

In this paper, safety principles, safety levels and safety services are studied for the development of information system with more importance to safety of hardware level, operation system level, database level, application program level and external system level by employing related safety technologies. During the development of application program level, a model of access monitor is raised with conclusion of constructing safe structural model of information system.

\section{REFERENCE}

[1]StePhen E.Dossick. WWW access to legaey Client/Server applieation. Computer Network and ISDN System, 1996, 28

[2]Cheswick. Firewall and inteenet security. Addison WesleyPress, 1994

[3]Chris to PherWKlaus. Network security: anything butbullet Proof Data Communications.1996.25

[4]Liang Shanhu, Du Pingan, Wang Zhihong etc.: Study on Modeling Method for Manufacturing Process based on O-O-T. IEEE International Conference on Intelligent Mechatronics and Automation (2004): 55-59.

[5] Jozsef Vancza\&Andras Markus. Experiments with the Integration of Reasoning, Optimization and Generalization in Process Planning. Advances in Engineering Software, 1996, 25:29-39.

[6].RObertCooley , BamshadMobasher , JaideePSrivastava , WebMining:Information and Patterndiseovery on the worldwidew 亡 b.[A], ICTAI' 97, Dee.1997

[7].C-HYun, M.S.Chen, Mining Web Transaetion Patterns in an Electronie Commerce Environment, [J], Proc.of the $4^{\text {th }}$ Paeifie - Asia Conf. on Knowledge Diseoveryand Data Mining (PAKDD - 00), 2000, 4:216 - 219

[8].RAgrawal, TImielinski, A Swami. Mining Assoeiation Rules Between Set of items in Large Database[J], Prco. ACMSIGMOD, 1993, 5:207-216

[9]- R Kosala, H Blockeel, Web Mining Researeh: A Survey[J], SIGKDD ExPloration, 2000, 2(1):1-15

[10]32.Zaiane0.R., HanJiawei, Resource and Knowledge Diseovery inGlobal In formation System: A Preliminary Design and Experiment in Proe of KDD, 1995, $331-336$

[11] F.L.Zhao, S.K.Tso, Paul S.Y.Wu. A cooperative agent modeling approach for process planning. Computer in Industry. 41(2000): 83 97.

[12].Brian-lent, Arun swami and Jennifer Widom, Clustering Association Rules, Proc.of the-3th International conference on Data Engineering. Birmingham, UK, Apr.1997, 220-231. 